\title{
The Road to Paradise: Moral Reasoning in Addiction Publishing
}

\author{
Thomas McGovern, Thomas F. Babor and \\ Kerstin Stenius
}

With the gesture of a guide, whose goal's in sight, She spoke: "We from the greatest body move, Emerging in the heaven that is pure light; Light of the understanding, full of love, Love of the true good, full of joy within, Joy that transcends all the heart conceiveth of."

Dante Alighieri (1947), Paradiso, Canto XXIX, 37-42

\section{Introduction}

The descent into the various levels of the Inferno, described in Chapter 14, resulting from the capital sins (vices) associated with varying degrees of scientific misconduct, is replaced in this chapter by a description of an ascent into Paradise, a realm of enlightened ethical conduct and decision making. This transformation is achieved by the practice of virtue and by adherence to ethical principles and moral reasoning. The ascent into the heavenly spheres is achieved by those virtuous ones who exemplify fortitude, prudence, justice, and temperance in the overarching context of faith, hope, and love. "Being good" (character ethics) exemplifies this state, and this is a quality found in society,

\section{How to cite this book chapter:}

McGovern, T, Babor, T F and Stenius, K. 2017. The Road to Paradise: Moral Reasoning in Addiction Publishing. In: Babor, T F, Stenius, K, Pates, R, Miovský, M, O’Reilly, J and Candon, P. (eds.) Publishing Addiction Science: A Guide for the Perplexed, Pp. 299-321. London: Ubiquity Press. DOI: https://doi.org/10.5334/bbd.o. License: CC-BY 4.0. 
institutions, and individuals. Moral reasoning and ethical reflection inculcate attitudes that promote good behavior, the moral stance of "being good."

Reflection and conversation are at the heart of ethical dialogue in any setting. The road to the unethical publication pitfalls described in the previous chapter is paved with good intentions. Perhaps "good conversation" is equally a culprit, as discussion about ethical issues in research does not seem to have influenced actual behavior. Kass (2002), a seasoned veteran in the field of bioethics, complained that "in bioethics at the present, the action is mostly talk" (p. 57). In our search for the best solution to ethical problems, we have lost sight of the original goal of ethics: to improve the quality of our behavior. How then can we provide meaningful direction for researchers wishing to avoid the seven deadly sins pertaining to scientific writing and fraudulent research and at the same time devise a virtuous path leading to responsible research?

Let us abandon ethics as good conversation, an approach advocated by many respected authorities (Brody, 1990; Glaser, 1994), and concentrate exclusively on practical recommendations to guide the behavior of authors and researchers. The Greeks, in their wisdom, saw virtue - the quality of being good in any human endeavor-as the condition of being poised between the two extremes (vices) of any given situation. In proposing an approach to ethical issues in addiction research and publishing, we embrace the advice of the Greeks, which accounts for both talk and action in fashioning practical responses to moral questions.

In pursuing a path that leads to ethical behavior guided by moral reasoning, we find guidance in the initiatives promoted by the International Society of Addiction Journal Editors (ISAJE) and by the Committee on Publication Ethics (COPE). ISAJE was organized in 1997 and has authored the Farmington Consensus (1997) and Ethical Practice Guidelines in Addiction Publishing: A Model for Authors, Journal Editors and Other Partners (ISAJE Ethics Group, 2002). Since its own inception in 1997, COPE has published guidelines, policy statements, and more than 500 case reports that provide guidance in promoting ethical standards in all aspects of publication while at the same time addressing the pitfalls of unethical behavior and the associated vices described in Chapter 14. Table 15.1 describes the types of the cases covered by COPE in its ethical analysis of moral problems associated with overall research, including addiction research. The data show that a wide variety of ethical problems have precipitated inquiries for ethical analysis, especially with regard to questionable and unethical research. Most of these issues have already been discussed in Chapter 14. COPE also provides a variety of policy statements and guidelines that address major issues in publication from the perspective of publishers and editors and issues resulting from the case reports described above.

We begin with some reflection about ethics as the human endeavor in addiction research. This approach to ethics is characterized by twin goals: "to be good" and "to do good." Being good is at the heart of "virtue" or "character" 


\begin{tabular}{|l|c|c|}
\hline \multicolumn{1}{|c|}{ Type of case } & Frequency & Percentage \\
\hline Questionable and unethical research & 167 & $21.1 \%$ \\
\hline Redundant and duplicate publication & 113 & 14.3 \\
\hline Data sloppiness, fabrication, etc. & 105 & 13.3 \\
\hline Misconduct/questionable behavior & 99 & 12.5 \\
\hline Correction of literature & 82 & 10.3 \\
\hline Conflict of interest & 61 & 7.7 \\
\hline Plagiarism & 55 & 7.0 \\
\hline Miscellaneous & 54 & 6.8 \\
\hline Peer review & 54 & 6.8 \\
\hline TOTAL & 790 & $100 \%$ \\
\hline
\end{tabular}

Table 15.1: Frequencies, percentages, and types of ethical cases covered by COPE.

Source: Frequency data obtained from COPE website: http://publicationethics. org/cases, accessed June 21, 2015.

ethics and espouses qualities such as integrity, honesty, and compassion for others. Doing good is the basis for principle-based ethics, such as autonomy, beneficence, and justice (see Table 15.2 for definitions of italicized ethical terms).

We combine both goals in the ethical discussion in this chapter and bring them to bear on two basic questions that are interwoven in every research enterprise: (a) Can we do it (the technical or research question), and (b) should we do it (the ethical or moral question)? Both questions, individually and collectively, are challenging: They hold us to equally rigorous scientific and ethical standards in all of our research and publishing undertakings. The materials produced by COPE are also an invaluable resource in this undertaking.

\begin{tabular}{|l|l|}
\hline Autonomy & $\begin{array}{l}\text { Respect people's choices, and do not obstruct their actions } \\
\text { unless those actions are harmful to others. }\end{array}$ \\
\hline Beneficence & $\begin{array}{l}\text { Do good: Provide competent and compassionate care and } \\
\text { maximize benefits to individuals, institutions, society. }\end{array}$ \\
\hline Nonmaleficence & $\begin{array}{l}\text { Do no harm: Minimize risks to individuals, institutions, } \\
\text { society. }\end{array}$ \\
\hline Justice & Give each person his or her due. \\
\hline Fairness & Avoid discrimination and exploitation. \\
\hline Stewardship & Use resources efficiently and justly. \\
\hline
\end{tabular}

Table 15.2: Key ethical principles used in moral reasoning and decision making. 


\section{The Ethical Challenge}

Scientific issues in the addiction field, as elsewhere, embrace three ethical realms: the individual, the institution, and society (Glaser, 1994). In affording respect to each of these realms, researchers honor what Kass (2002) describes as "the rich broth of our social, civil, cultural, and spiritual life together and of the ways in which it seasons us without our knowledge" (p. 65). The well-being of the individual, of institutions, and of society as a whole is at stake in assessing the ethical issues that arise in addiction research, as illustrated by recent studies of corporate social responsibility programs, research on chronic drug users, and the use of animals involved in addiction research (Casswell, 2013; Fisher, 2011; Lynch et al., 2010; Miller et al., 2011). Consider the following scenario as an invitation to apply our discussion up to this point to the realities of a possible research publication situation:

A university research team wishes to examine drug use in a poor, disadvantaged minority neighborhood with an identifiable ethnic population. The intent of the study is to test a new treatment for addiction that holds great promise for society as a whole. The political climate in which the research is conducted is one that is willing to provide research support for biological and social research but is not prepared to address the deeper societal issues underlying drug problems. In addition, the community in which the research is to be conducted sees drug use as both a matter of choice and best controlled through stringent and oppressive legal measures. Furthermore, the larger community views the minority drug-using group with suspicion and distrust. The individuals who will constitute the research population are disadvantaged, have little education, and are a vulnerable population that can be easily exploited in a research endeavor.

Can such research be conducted in a manner that meets appropriate scientific standards? The answer is yes: Many measures can be taken to assure its appropriateness. For instance, researchers can offer guarantees that ensure respect for the dignity of the research participants. Researchers can also safeguard the vulnerability of the individuals involved, together with the community as a whole, by meeting the standards of ethical review committees and other governmental and institutional regulations on research. At first sight, the ethical and scientific standards for responsible research seem to be met at the individual level.

But what of the larger community and societal implications of this research? How will the individuals involved be treated by the larger community if the study shows a high prevalence of drug dependence in the population? Conceivably, an increase in discrimination and oppression might occur (McGovern, 1998), a result researchers would want to avoid. Another consideration centers on who shall benefit from the favorable outcomes of 
the research: the individuals in the poor neighborhood or the more privileged members of society? Balancing individual, institutional, and societal concerns can lead to a better understanding of the risks and benefits of research in such situations. Whether or not such research should be undertaken determines whether or not it is published.

A helpful perspective on research and publishing as a whole, as well as the case under consideration, can be found by applying the theories and principles associated with "doing good." In analyzing the proposed scenario, a utilitarian approach might seek to maximize the good and minimize the harm. In its most simplistic application, utilitarianism is based on the maxim that the end justifies the means. One could argue from this perspective that the benefit accruing to the majority of the population outweighs the harm to the individual research participants. A duty-driven or deontological approach would counter by arguing that humans can never be used as a means to an end, that their basic dignity must be valued as an end in itself. Two very different responses to the legitimacy of the research and of its subsequent publication thus result from invoking the utilitarian and the deontological positions. One must always be skeptical of research and publications that are justified on the basis of utility or expediency. Grave harm can be inflicted on minority populations and on persons unable to adequately protect their basic dignity (Elwood, 1994). Such a caveat needs to be heeded by authors and editors alike.

In following the road to ethical paradise in research and in publication, then, it is helpful to remember a number of principles derived from ethical theory. Autonomy, or respect for persons, obliges the researcher in our scenario and those who oversee research to respect the dignity of those involved in the research project. This is guaranteed by safeguarding privacy and confidentiality and by receiving informed consent-with special attention given to assure that research participants fully understand the risks and benefits involved in the study. Likewise, the principle of nonmaleficence-that is, doing no harm to individuals, communities, and society as whole-is of the utmost importance. Conducting research in a competent and compassionate fashion is embodied in the principle of beneficence. Although often criticized as the basis for a paternalistic approach, this principle is indispensable in addressing the needs of vulnerable individuals and vulnerable communities, as in the scenario under consideration.

The ethical principle of justice guarantees persons their due and guards against discrimination. We would invoke this principle to ensure that we do not expose the research population to undue risks for the benefit of another population. Fairness, as a guiding principle, is difficult to invoke in a society overzealous in its defense of individualism and autonomy, without equal attention to the common good (see Ross et al., 1993, pp. 17-28, for discussion of these principles). Finally, stewardship demands that investigators use resources responsibly and efficiently. 


\section{Toward a Problem-Solving Approach}

The first step in the development of an effective problem-solving approach to ethical dilemmas in addiction publishing is to create a code of professional practice for use by research organizations and scientific journals. Such a code now exists in the form of the ethical practice guidelines developed by ISAJE (ISAJE Ethics Group, 2002). The ISAJE guidelines articulate values and define the boundaries of appropriate and inappropriate conduct in addiction research. As such, they provide a moral compass authors can use to guide ethical decision making. One should also note the very significant contributions of COPE in providing moral direction in our research undertakings.

However, the most enlightened and practical direction might be found in the comprehensive analysis of actual situations, especially if they can be considered paradigm cases. This approach finds expression in casuistry, with its ancient roots in moral philosophy and in theology, which provides a consistent focus on individual moral behavior (Jonsen \& Toulmin, 1988). It values broad consensus, the development of maxims based on practical wisdom, and the acceptance of probable certitude as the ultimate outcome. Casuistry is attractive because it most closely resembles how we approach moral issues in day-to-day living. Brody (1990) argues that if we examine any ethical situation in research or publishing from every possible angle, we will be able to arrive at a consensus and, in doing so, cover all the various ethical approaches, including theory and principles. The case reports and ethical analysis provided by COPE, which have been previously referenced, are also an invaluable resource in this respect.

Another necessary step toward ethical decision making is to learn how to apply these codes in a practical way. To this end, the main part of this chapter is devoted to the analysis of a set of case studies. These cases are presented in the form of short vignettes that describe a situation or problem, followed by an analysis of the ethical principles involved and the appropriate course of action to be taken by the author. The vignettes have a touch of humor in their presentation, intended as a relief from the doom and gloom of traditional moral analysis. We have also organized the incidents depicted in the vignettes according to the following topics:

1. citation bias: a selective reporting of the literature;

2. redundant publication: when two or more articles share any of the same data or text without full cross-referencing;

3. unethical authorship: all persons named as authors should have made a major contribution to a publication and be prepared to take public responsibility for its contents;

4. undeclared conflict of interest;

5. failure to conform to minimal standards of protection for animal or human subjects;

6. plagiarism: unreferenced use of others' published and unpublished ideas; and

7. scientific fraud. 
The analyses provide guides to action, rather than definitive decisions, by deriving conclusions about the most appropriate course of action from sound (and, for the most part, universal) ethical principles such as autonomy, beneficence, justice, honesty, conscientious refusal, stewardship, and nonmaleficence.

\section{A Synthetic Model for the Analysis of Ethical Dilemmas}

In their book, Critical Incidents: Ethical Issues in the Prevention and Treatment of Addiction, White and Popovits (2001) describe a synthetic model for ethical decision making that borrows from the major traditions and ethical principles described above. The goal is not to provide definitive answers to difficult ethical choices but rather to stimulate thinking about ethical complexity and to suggest options for an ethical course of action. The model involves the application of three questions:

1. Whose interests are involved, and who can be harmed? Stating this question in another way, who are the potential winners and losers? In the situations described in this chapter, the main parties likely to be involved are the authors of a particular journal article, the editor of the journal, the author's co-workers, the institution with which the author is affiliated, the professional community of addiction researchers, and society at large. By reviewing the interests and vulnerabilities of these different stakeholders, it becomes possible to identify areas of conflicting interest, where the benefits to one party must be balanced against the harm that could be done to another party or institution.

2. What universal or culturally specific values apply to this situation, and what course of action is suggested by these values? According to White and Popovits (2001), this question requires one to explore how widely held ethical values (defined in Table 15.2) can be applied to guide the best course of action in a particular situation. The identification of values that may be in conflict (e.g., honesty vs. loyalty) is an important part of this process, leading to a resolution of the conflict by choosing the higher value. White and Popovits indicate that "the higher value is often determined by the degree of good to be achieved or the degree of harm to be avoided [as] identified through the first question" (p. 27).

3. What standards of law, professional propriety, organizational policy, or historical practice apply to this situation? The third step in this process involves the review of established standards of professional conduct, which prescribe or proscribe certain actions for the situation in question. These standards include legal mandates (e.g., copyright laws), professional practice standards, human-subjects requirements, and institutional policies. 
Incident/situation

1. Whose interests are involved; who can be harmed, how serious is the potential harm? Which interests, if any, are in conflict?

\begin{tabular}{|l|l|l|l|}
\hline & significant & moderate & minimal/none \\
\hline Your own interests & & & \\
\hline Co-workers & & & \\
\hline Research participants & & & \\
\hline Your institution & & & \\
\hline Professional field or science & & & \\
\hline Society & & & \\
\hline
\end{tabular}

2. Application of universal values. Check all that apply to your case. Autonomy (freedom over one's own destiny) Beneficence (do good, help others) Nonmaleficence (do not hurt anyone) Justice (be fair, distribute by merit) Obedience (obey legal and ethically permissible directives) Conscientious refusal (disobey illegal or unethical directives) Gratitude (pass good along to others) Competence (be knowledgeable and skilled) Stewardship (use resources wisely) Honesty and candor (tell the truth) Fidelity (keep your promises) Loyalty (do not abandon) Diligence (work hard) Discretion (respect confidence and privacy) Self-improvement (be the best that you can be) Restitution (make amends to persons injured) Self-interest (protect yourself) Other culture-specific values

3. What laws, standards, policies, practice guidelines, and historical practices should guide us in this situation?

Box 15.1: Checklist for analysis of critical incidents. Adapted from White and Popovits (2001). 


\section{Case Studies}

In this section, we present seven case studies, each dealing with an important ethical dilemma. Following each case are a series of discussion questions that draw attention to the moral reasoning issues covered. After considering these questions, the reader should follow the outline shown in Box 15.1, which provides further guidance about how to resolve a particular dilemma. Then compare your responses with the ethical analysis that follows each case, which is conducted according to the moral reasoning procedures proposed by White and Popovits (2001). A further source of case discussion and ethical analysis is found in the materials published by COPE, which provides ready access to case materials, including ethical analysis, under the following headings: authorship, conflict of interest, consent for publication, contributorship, data, editorial independence, funding/sponsorship, miscellaneous (books, social media, legal issues), misconduct/questionable behavior, mistakes, peer review, and plagiarism. In the discussion of the cases that occur in this chapter, ethical opinions from COPE are included in the ethical analysis of the cases we have chosen.

\section{Case 1. Selective Reporting of the Literature}

Mr. C. Lective is a graduate student in clinical psychology at Orgone University who has just finished his doctoral dissertation under the direction of his mentor, the prominent clinical psychologist Prof. Ann Dorphin. The dissertation topic was based on Prof. Dorphin's Theory of Addiction Reflection, which proposes that drug users' brainwaves give off an aura of escaping endogenous opiates that can be captured by perceptive therapists and recycled to form a therapeutic alliance. After several promising quasi-experimental studies and case reports of Addiction Reflection therapy, all published by Prof. Dorphin or her students, two independent randomized trials produced negative results. A review article was then published questioning the validity of the theory as well as the unorthodox research methods used at Orgone University. Consistent with previous studies at Orgone University, Mr. Lective's dissertation has produced positive but unimpressive results in support of the theory. Prof. Dorphin strongly suggests that the results be published and collaborates in the drafting of an article that recommends that Addiction Reflection therapy be adopted widely in routine clinical practice. The article is submitted to a small psychotherapy journal. After receiving the reviews, the editor of the journal writes the following letter to Mr. Lective:

"I have now received two reviews of your manuscript. The first reviewer liked the article and has few recommendations for revision. The second reviewer, however, notes that your literature review fails to describe recent studies of Addiction Reflection therapy, including a highly critical review article, and thereby presents an inaccurate and misleading characterization of the current status of the theory. Although your study does not seem to contain any fatal flaws, I have decided 
not to accept the article because of the reviewer's criticism that the background, rationale, hypotheses, and discussion are all in need of major revision, and the level of scholarship reflected in the article's introduction suggests that the authors are either unfamiliar with recent research on the topic or are being unusually biased in their reporting of the background to their study."

\section{Discussion Questions}

1. What could Mr. Lective and Prof. Dorphin have done to avoid this situation?

2. Who is responsible for the selective reporting of the literature, the first author (Mr. Lective), the second author (Prof. Dorphin), or both?

3. Whose interests are involved, and what ethical principles apply to this case?

\section{Ethical Analysis}

The responsibility for providing a complete account of the literature and research pertaining to Addiction Reflection therapy rests with both authors, with Prof. Dorphin shouldering most of the responsibility because of her supervisory position. Selective reporting of the literature to support a particular point of view is a significant ethical infraction. It clearly deviates from accepted standards of citation, as described in Chapter 10. Using the WhitePopovits grid (see Box 15.3) for the analysis of critical incidents as a guide, this ethical violation has significant moral implications for the authors, their institution, the addiction field, and society as a whole. The reprimand that the authors received from the editor, together with the rejection of the manuscript and the accompanying professional embarrassment, is minor inconvenience compared with the greater harm that might have resulted from the publication of their work. Consider how their faulty research might have harmed the wellbeing of clients being treated by service providers who, in good faith, followed the researchers' clinical recommendations.

The authors' actions, probably motivated by self-interest, violated the ethical principles of nonmaleficence and justice. There is a clear mandate to "do no harm" enshrined in the principle of nonmaleficence. Mr. Lective and Prof. Dorphin's lack of honesty in espousal of self-interest has the potential to endanger the well-being of all clients and institutions involved with the new therapy. In addition, the principle of justice (fairness) becomes relevant when one considers the fruitless expenditure of scarce resources on a futile mode of treatment. In addition, Prof. Dorphin is clearly in a position to violate the student's autonomy (self-determination) by bringing undue pressure on him to publish his research in a manner supportive of her original theory. This form of coercion, 
which is clearly unethical, is often ignored in research situations, with consequences for everyone involved when this is uncovered. Much of the harm, real and potential, involved in this situation could have been avoided by following the established standards of citation practice-that is, to present all sides of the related literature, as described in Chapter 10. COPE provides further insight into the ethical issues raised by this case in their discussion of the potential fabrication of data in primary studies included in articles for publication (http:// publicationethics.org/cases; Case number 14-01 2014).

\section{Case 2. Redundant Publication}

A junior faculty member, Dr. Salame Science, is approaching tenure review at a large university that places great emphasis on the number of first-authored publications as the main criterion for promotion. Dr. Science, who has been working with three other investigators on a large collaborative survey study, suggests that the investigators report their findings separately for each of 16 drugs, thereby giving each of the investigators four first-authored publications. Dr. Science develops a template in which the literature review, methods, and statistical analyses are virtually the same for each article, with only the name of the drug being changed for the 16 articles. When one of the articles dealing with a new rave drug is submitted to a journal for review, the authors fail to advise the editor of the other 15 articles under review at different journals, and do not cite any of these articles in their report. Moreover, the co-authors all sign an ethical statement required by the journal indicating that the article has not been published in whole or in part by another journal and is not under consideration by another journal.

\section{Discussion Questions}

1. What should Dr. Science and her co-investigators have done with the reporting of the survey findings?

2. What, if anything, should they have told the editor at the time they submitted the manuscript?

3. Whose interests are involved, and what ethical principles apply to this case?

\section{Ethical Analysis}

As noted in Chapter 14, a place in Hell is reserved for those guilty of promoting their own self-interest in the practice of redundant publication, in violation of accepted ethical norms. Dr. Science and her three collaborators find themselves in this unholy situation by submitting material that is (partially) 
under consideration by another journal and by using verbatim material without quotation marks or attribution. By signing the journal's ethical statement, they have blatantly lied about the existence of the other articles and their relationship to the rave drug study.

Thus, however inadvertent it initially appears, the deception involved in failing to disclose the relationship between the articles has serious ethical implications. Referencing again the White-Popovits analysis grid (see Box 15.1), several types of harm can result at professional, clinical, and societal levels. First, if all 16 articles were in fact published (as opposed to one or two comprehensive articles), the authors would deny as many as 15 competing and perhaps equally worthy authors of the opportunity to publish in the same journals, because many journals have limited space and must reject a high proportion of submitted articles. Second, the task of reviewing and processing these redundant articles creates unnecessary work for reviewers and editors, most of whom volunteer their time as a service to the peer-review system. Whether the possible harm rises to the level of significant in the White-Popovits grid is debatable; it is certainly moderate, in terms of harm inflicted by any standard of ethical analysis. Clearly, the authors' actions have violated the standards of honesty, candor, fidelity, and diligence. The decision of the authors to lie in their ethical declaration attacks the basic trust that undergirds the scientific enterprise and has the capacity to inflict the type of "irreparable damage to scientific investigators, editors, and the community" described in Chapter 14.

By following established standards for citing the interrelationships involved in their collaborative studies, and by responding honestly to the statement required by journal editors and publishers, the authors could have avoided both the ethical and legal censure resulting from their deception and dishonesty.

A case report from COPE (number 06-22 2006) provides further insights into the ethical issues created by redundant publications (http://publicationonethics. org/cases/).

\section{Case 3. Authorship Credits}

Dr. Mary Doogood is a postdoctoral fellow at the prestigious National Addiction Research Collaborative (NARC). She is conducting research on prescription-drug addiction under the direction of her mentor, Dr. Arthur Stringalong. After a preliminary analysis of the findings, Dr. Stringalong (who helped design the study, secure grant funding, and analyze the data) suggests that they prepare an article for submission to the Journal of Irreproducible Results.

When Dr. Doogood finishes the first draft, Dr. Stringalong insists on two additions to the list of authors: (a) the scientific director of NARC, who had nothing to do with the study or the writing of the manuscript, and (b) the research assistant who conducted the interviews, entered the data, and did a literature search but who otherwise had little involvement in the study design, data analyses, 
interpretation of findings, or drafting of the manuscript. Dr. Stringalong tells Dr. Doogood that with the NARC director as last author, the article would have a better chance of being accepted by the Journal of Irreproducible Results. He also suggests that the research assistant, Ms. Day Tamanager, deserves to be listed as a reward for her hard work; a publication credit will help her application for admission to graduate school.

\section{Discussion Questions}

1. Whose interests are involved, and what ethical principles apply to this case?

2. What should Dr. Doogood do about the suggestion to add the name of the scientific director of NARC?

3. What should Dr. Doogood do about the suggestion to add the name of the research assistant?

\section{Ethical Analysis}

One could argue that this situation has significant ethical implications for Drs. Doogood and Stringalong on an individual basis and moderate implications for the scientific director and the research assistant. Dr. Stringalong violates Dr. Doogood's autonomy as first author by insisting on the addition of the extra names, although he would not violate her autonomy if he merely suggested it. Dr. Stringalong's insistence is all the more egregious because of the implications of the duress deriving from his position of authority. There are also issues of doing no harm and of fairness, understood as distribution of credit according to merit. Ms. Tamanger, the research assistant, may have some claim to coauthorship from a fairness perspective but does not really meet the criteria for authorship described in Chapter 11 of this book. Of course, Dr. Doogood could include both in the acknowledgment section without violation of the rule of appropriate attribution-of-authorship credit. Should the names be included as co-authors, an argument could be made that the profession, the field, and society could be moderately damaged.

Dr. Stringalong might counter, from a utilitarian viewpoint, that using the scientific director's name to assure the publication of the data would work toward the betterment of individuals and society and, thereby, outweigh the harm involved by including the additional author. He might likewise remind us that names are regularly added to lists of authors without being seen as a major ethical violation.

The counter-argument points to the damage, certainly moderate and possibly significant, inflicted on the field by the violations of honesty, equity, fidelity, and loyalty involved in this practice of gift authorship. It is clearly contrary to 
the practice guidelines endorsed by journal editors over the past several decades. In summary, the issues raised in this case involve ethical violations at the individual, institutional, and societal levels and therefore cannot be justified.

\section{Case 4. Undeclared Conflict of Interest}

Dr. Boyam I. Greedy was asked by the editor of the Journal of Neuropsychopharmacoepidemiology (NPPE), Dr. Tom Naïve, to submit a review article on the subject of anti-dipsotropic medications. Dr. Naïve based his invitation on Dr. Greedy's expertise in the pharmacological treatment of craving and his widely cited articles on a new anti-craving drug called Payola. Dr. Greedy prepared the review and submitted it to the journal editor. In the article, Dr. Greedy cited both published and unpublished reports to support his contentions that:

- anti-craving drugs like Payola reduce drug craving and substance abuse;

- a large multi-center clinical trial of Payola is currently underway by the manufacturer, Chemical Therapeutics, Inc.; and

- methods to deliver Payola via patch technology have been developed.

Because the Journal of NPPE has no formal policy, Dr. Greedy was not asked to declare any real or apparent conflicts of interest. In addition, in the acknowledgements section of the article, Dr. Greedy included pertinent information about the people who helped him prepare the article. But neither his communications with the editor nor the acknowledgements section revealed the following information:

- Dr. Greedy holds U.S. Patent 6,375,999 on "Methods and Devices for Transdermal Delivery of Payola."

- Dr. Greedy is a member of the scientific advisory board of Chemical Therapeutics, Inc., and as such received an option to purchase 7,000 shares of stock at 5 cents per share. When the projected initial public offering of shares by Chemical Therapeutics, Inc., occurs in the near future at the corporation's estimated share price of $\$ 25.00$ per share, Dr. Greedy's equity will be valued at $\$ 175,000$.

- Dr. Greedy received substantial consulting payments from Chemical Therapeutics, including first-class airfare to numerous international meetings, where he spoke about his research on Payola.

\section{Discussion Questions}

1. What ethical issues could arise in this convergence between Dr. Greedy's role as a scientist writing a review article and his connections with the drug company, Chemical Therapeutics, Inc.? 
2. To what extent does Dr. Greedy stand to gain financially by gratuitously promoting his patented Payola patch?

3. To what extent does Dr. Greedy stand to gain financially from the interest that his positive assessment of Payola might generate for Chemical Therapeutics, Inc., in advance of a public stock offering?

4. What are the real or apparent conflicts of interest in this case?

5. What are Dr. Greedy's ethical obligations in this case?

\section{Ethical Analysis}

Dr. Greedy has many personal, professional, and financial interests embedded in the promotion of Payola. His ability to influence a wider public and to advance the acceptance of the new drug is closely tied to the publication of his review article. A real conflict of interest exists and a host of ethical concerns arise at the individual, institutional, and societal levels.

At the outset, it is important to establish the stakeholders-that is, those who are likely to benefit or lose from the publication of a review article that fails to acknowledge the author's financial stake in Payola's development. First, the author stands to profit in many ways from the publication of the review, although the extent of this benefit depends partly on the prestige of the journal and its influence on readers. Second, patients experiencing addiction stand to gain if knowledge of the efficacy of the new medication becomes widespread following the article's publication.

In his defense, Dr. Greedy might say that the promotion of the new product was the province of the advertising arm of Chemical Therapeutics, Inc., and that neither he nor the company would benefit unduly from the publication of the review article itself. He might even add that his ownership of the patent and his financial ties to the company were matters of public record and these activities are perfectly legal and ethical (even in academic circles) in his role an entrepreneur-scientist. He made his decision to publish his findings solely out of respect for the editor, Dr. Naïve. If the journal had a disclosure policy about conflict of interest, he would have had the option of either complying with it or declining the invitation to publish his data.

Another important set of stakeholders in this case includes the journal itself, its editor, and the publisher. An objective bystander might question the professional and ethical judgment of the editor, Dr. Naïve, in inviting Dr. Greedy to submit an article without first consulting the editorial board. Here Dr. Naïve has failed in his fiduciary responsibilities to the author, the publisher, the journal, and its readers. Even if Dr. Greedy's review were fair, balanced, and critical, deserving of the broadest possible dissemination, the integrity of both the journal and the field are nonetheless called into question by Dr. Naïve's lack of responsibility. The absence of a conflict-of-interest disclosure policy excuses neither the editor nor the author. In a like vein, neither Dr. Greedy nor 
Dr. Naïve should claim that the possible good resulting from the publication of the review article outweighs the harm done. One could further argue that if this practice of nondisclosure became widely accepted, irreparable harm could result for patients, the publishing field, and society as a whole.

This case gives us pause when we acknowledge a certain reluctance on the part of the entire scientific community-in its individual, academic, and research components-to provide full disclosure. The relationship among research, industry, and publishing outlets is a necessary one, but ethical standards are needed to manage conflicts between self-interest and concern for the common good.

COPE, in many of its case reviews and related publications, emphasizes the importance of addressing conflict of interest as an ongoing issue of ethical concern in the publication of research. In a case titled "Multiple failure to declare a relevant conflict of interest" (case number 07-33 2007), it provides excellent guidance on how to deal with situations like this.

\section{Case 5. Human Subjects Requirements}

Dr. X. Ploit, a clinical psychologist working at the Department of Parole, hears about a dataset consisting of clinical records, demographic information, and rearrest data for parolees (i.e., convicted criminals who are released to the community under close supervision) who were exposed to a new substance use disorder treatment program. Because the program could not accommodate all parolees, only people being released from prison on alternate weeks were assigned to the program. The others received no treatment. When Dr. Ploit learns of this "natural experiment," he concludes that the data could comprise a very valuable contribution to the literature, because the parolees were, in effect, randomly assigned to treatment and control conditions and were not pre-selected for participation in a research project. Because of his lack of ethical training, Dr. Ploit is unaware of the need to obtain ethical review board approval to access these kinds of records for research purposes, even though he has legitimate access to the same records because of his clinical responsibilities. Thus, he obtains the names of the selected paroled prisoners, looks up their remand records, and conducts a statistical analysis. The analysis reveals that the parolees who were exposed to treatment were significantly less likely to return to prison for parole violations associated with alcohol and other drug use. Dr. Ploit writes up the results and submits them to the Journal of Drug Criminalization.

When he submits the article, Dr. Ploit is asked to sign a form stating that the study had received all necessary human subjects approvals by an ethical review board. Although Dr. Ploit feels conflicted about signing the statement, he decides to lie about his failure to seek ethical approval, reasoning that (a) the results do not identify individual prisoners and (b) the ethical review board would probably have given him permission to access the data anyway. Dr. Ploit also hesitates to 
seek post hoc permission from the ethical review board at this point, because they might now deny permission. He reasons that the value of the findings for society and the prisoners far outweighs his minor ethical transgression.

\section{Discussion Questions}

1. Why did the editor require Dr. Ploit to submit documentation that he had met ethical review requirements for the study?

2. What is the function of institutional and editorial requirements regarding the treatment of human participants?

3. Do compliance standards in themselves assure ethical behavior in research?

\section{Ethical Analysis}

In this case, it is appropriate to emphasize the vulnerability of persons with addictions in all aspects of their well-being, including treatment and research, and the intensification of such vulnerability in particular environments, such as correctional facilities. Such concerns are central to Dr. Ploit's research, which describes the response of parolees to an innovative treatment program. Even though the way in which participants were originally assigned to the new treatment arose out of limited resources, ethical review is very important to make sure that coercion was not a factor. These questions arise in the presence or absence of a research protocol.

The question of ethical approval, requested by the editor as a condition for accepting this piece for review, is an important one. Ethical review gives some assurance that the research itself meets basic ethical standards and also includes the expectation to provide oversight of the ongoing research in terms of participant well-being in a research environment. The ethical review board, if it had been involved in the discussion of this research, could have decided that the research enjoyed exempt status under the rubric of quality assurance and chart review. On the other hand, it may have required full compliance with all the requirements of a regular research protocol. In addressing a journal's ethical concerns about compliance with ethical review committees or other supervisory bodies, the nature of Dr. Ploit's work changes when it becomes research. The editorial board could reasonably restrict Dr. Ploit's research to data gathered subsequent to approval.

Compliance with regulatory bodies generally satisfies legal requirements in research undertakings and guarantees that basic ethical standards are in place. The regulatory research bodies share with journal editors a concern for the promotion of good and the avoidance of harm at the individual, institutional, and societal levels. The author has a fiduciary relationship with the 
ethical review board and with the editor, and all parties are mutually dependent on each other acting in good faith and in compliance with a commonly accepted ethical framework that promotes the common good. Compliance standards in and of themselves guarantee minimum protection for stakeholders in research undertakings; ethical standards often espouse a higher degree of care.

The ethical dimensions involved with the protection of human subjects have societal, institutional, and individual implications. This has been discussed in the ethical analysis of this case, and further insight into this analysis is provided by the COPE publication on inadequate assurance of human research ethics for questionnaires, case number 12-33 2012 (http://publicationonethics.org/ cases/, retrieved June 3, 2015).

\section{Case 6. Plagiarism}

Wilhelm Reicht and Ena G. Orgone are new doctoral students working on a project at the University of Freudberg that explores the impact of the therapistpatient relationship in psychoanalytic treatment for female abusers of prescribed psychotropics. Reading the background literature, they find a very good article by Professor Eve N. Id in one of the big U.S.-based psychoanalytic journals. In the article, Dr. Id explores how the angle of the analyst's sofa can influence the level of subconsciousness that the patient is able to reach in therapy. The article establishes the so-called Divanaltitude theory.

The two ambitious students decide to submit an article to the Bayerische Zeitschrift für Psychoanalytische Alkoholstudien to demonstrate that they are on the cutting edge of current research. Their article, written in German, presents the Divanaltitude theory along with some findings from a small, local survey that the students conducted to learn what alcohol and other drug therapists think about the design of sofas in therapeutic settings. Reicht and Orgone inform the editor that they consider their text to be an overview and not a piece of original research.

The editor, who is not familiar with the Divanaltitude theory, sends the text to a referee. The referee's critique comes back after two weeks. She has discovered that the introduction is a direct translation of Professor Id's abstract. Several subtitles and the structure of the first part of the article are identical to Dr. Id's. That the authors have one reference to Dr. Id's article in the second paragraph of the text is obviously not enough; the referee considers this to be a case of plagiarism.

The editor subsequently sends a letter to the young authors stating that he cannot accept the article for publication because large sections of the text are identical to an already published article. He states that their submission breaches internationally accepted ethical rules of publishing and demands an explanation. The editor also informs the authors that he will send a copy of his letter to the head of their department at Freudberg. 


\section{Discussion Questions}

1. How could the students have avoided the reprimand of the journal editor and the possible censure of their chair and university?

2. What harm, real or potential, could result from the students' action?

3. Could the students claim that they were unfamiliar with the ethical rules of publishing? If they were unfamiliar, whose obligation was it to inform them?

\section{Ethical Analysis}

The students' plagiarism has important implications, with the possibility of harm for the students themselves, the original author, the research institution, the addiction field, and for society as a whole. The students, according to the White-Popovits grid, exposed themselves to the risk of possible dismissal from their doctoral program as punishment for their violation of accepted ethical norms. It is conceivable, however, that they acted out of ignorance and that they had not received appropriate ethics training from their professors or their institution. Had the individual professors and the institution been remiss in providing appropriate direction for the students, then the institution and its representatives would be as culpable as the students.

The actions of the students obviously involved a form of theft where Dr. Id's work is concerned, but any damage to her reputation will be moderate or minimal according to the White-Popovits scale. Their transgressions also present the possibility of injuring the professional field and society as a whole, especially if such actions were to become commonplace in the publishing field. According to the White-Popovits scheme of universal values, the students violated the values of justice, honesty, and diligence in their failure to acknowledge the work of the original author. They acted out of self-interest, with lack of regard for established ethical and professional guidelines. They might be accused of violating the original researcher's autonomy by denying her the opportunity to control her own work through appropriate citations. If the students failed to receive appropriate ethical formation and direction from their institute, then the administrators and professors at the institute would be in violation of the principles of beneficence and nonmaleficence. Institutions have a moral responsibility to provide an environment in which integrity and honesty are an essential part of their research undertaking (Institute of Medicine, 2002). Stewardship also enters into the equation because, from a societal perspective, institutions have a social responsibility to use resources wisely.

The need to address plagiarism in its many forms, including self-plagiarism, is central in maintaining the integrity of research publication, with ongoing attention to the ethical dimensions addressed in the analysis of this case. In examining a report of possible self-plagiarism, COPE case number 14-10 2014 
provides further insight into this important issue (http://publicationonethics. org/cases/, retrieved on June 3, 2015).

\section{Case 7: Scientific Fraud_-Data Trimming"}

Dr. Frank N. Stein is a junior faculty member in the Department of Anatomical Protuberances at a large Transylvanian medical school. His latest research project deals with the effects of brain transplants on addiction careers. Preliminary analysis of the data on the first 10 transplants shows an interesting trend, but the $\mathrm{p}$ value is just shy of statistical significance. Dr. Stein's statistician, Mr. Igor Numbers, suggests they conduct a few more transplants to increase statistical power and then add an equal number of cases to the control group (without the benefit of random assignment). Igor also suggests they conduct a one-tailed test to get a more favorable alpha level and drop some of the covariates to increase the degrees of freedom. After Dr. Stein and Mr. Numbers have made all these protocol changes, they submit their article for publication as a true random assignment study with significant differences between groups. One of the reviewers questions the use of a one-tailed test, suggesting that the authors include more covariates in their analyses and asks the editor to obtain more detailed information from the authors (Dr. Stein and Mr. Numbers) about the way they assembled their samples. Dr. Stein's institution has granted appropriate approval for the research. In addition, the research enjoys societal approval through funding that provides appropriate resources for good scientific work.

\section{Discussion Questions}

1. Was it ethical for Dr. Stein to use the one-tailed test?

2. How should Stein respond to the editor?

\section{Ethical Analysis}

The stakeholders are the recipients, the scientists, the medical school, and society as a whole. The good espoused by Dr. Frank N. Stein's research is the enhancement of the addiction field through the advancement of knowledge about the effects of brain transplants. Whether to continue this research depends on outcome studies, largely dependent on the findings of Dr. Stein and Mr. Numbers, who are convinced that the changes in their statistical analysis are minor and ethical. They feel that the continuation of their work will confer immense benefits on all involved and especially people with addictive disorders. Their decision to use the new statistical analyses, together with their justification of this approach in their response to the review process, shows 
they believe the end justifies the means. After all, this is a new cutting-edge enquiry where data trimming on a minor scale may be considered no more than a minor peccadillo.

The researchers, despite their idealism and good intentions, are blind to the implications of honesty, stewardship, and fairness in their decisions. Their dishonesty impinges on the well-being and safety of the recipients of brain transplants. In addition, they are not good stewards of the funds that supported this research. Furthermore, their unethical use of funds constitutes disservice to the other, unfunded scientists whose requests for funding are based on honest and responsible findings.

Our tongue-in-cheek response to this fanciful scenario uncovers many ethical pitfalls resulting from what might appear prima facie as minor adjustments in one's statistical approach. Rigorous honesty must inform the research itself, and authors must be candid with editors about methods and outcomes. The relationship between the two parties is a fiduciary one, and the engendered trust touches the basic integrity of scientific publishing. Using the White-Popovits grid, one could award this case a perfect score of "significant" on all the interests and vulnerability items.

Fraud, as we have identified in the ethical analysis of this scenario, is the most egregious violation of professional integrity in research undertakings. COPE, in its analysis of case number 14-05 2014, again provides excellent insights into the implications of fraud in research situations (http://publicationethics. org/case/fraud-or-sloppiness-submitted-manuscript). Distinguishing between fraud and sloppiness is difficult to determine, and this case analysis is helpful in this respect.

\section{Conclusion}

The intent of this chapter was to illustrate an ethical framework that provides practical guidance for investigators in publishing responsible and trustworthy research. Central to this understanding is a high degree of trust, as demonstrated in the case analyses. A fiduciary relationship is at the heart of the assurance whereby researchers address the well-being of individuals, institutions, and the overall common good.

In a climate of self-interest, often nurtured by a high regard for an exaggerated form of individualism (which is inimical to the common good), it is difficult to develop a consistent appreciation of the place of trust in research undertakings, as is the case elsewhere in society (Institute of Medicine, 2002). Societal safeguards need to be in place, as envisaged by ethical review committees and other regulatory agencies, to ensure that the trust that individuals, institutions, and society afford to research is well placed and respected. Research communities and regulatory agencies need to establish the highest level of collaboration as a first step in creating and maintaining a climate of trust. 
Regulatory agencies in and of themselves cannot ensure ethical behavior in research or publishing, both of which have trust as their foundation. Other forces are in play, such as virtue or character considerations. Individuals, institutions, and publishing enterprises should ideally encompass qualities such as integrity, fairness, and trust in their undertakings evaluating the presence or absence of virtue in larger bodies is not easy. It is difficult to determine if an institution is virtuous based on an analysis of the goodness of the institution where the research occurs. Other forces are equally important, such as virtue or character considerations involving individuals and institutions in the research and publishing enterprises. Inserting virtue ethics by encompassing qualities such as integrity, fairness, and trust is not an easy task. Equally difficult is the infusion of like qualities into the culture of institutions where research occurs. Many centuries ago, in his dialogue with Socrates, Plato wrestled with this problem as recounted in his work, Meno: "Can you tell me Socrates, is virtue something that can be taught? Or does it come by practice? Or is it neither teaching nor practice that gives it to a man, but natural aptitude or something else?" (translation by Thompson, 1980). In fashioning a character-based ethic to guide the behavior of researchers and authors, traditional wisdom might prompt one to respond "all of the above" in answer to Plato's questions.

The "something else" to which Plato alludes is intriguing and invites comment as a concluding thought for this chapter. Perhaps Plato was hinting, for our present-day edification, that the fullest ethical analysis of persisting contemporary issues in research and publication, along the lines of the case studies in this chapter, is that "something else." Ongoing conversation about actual issues is the best assurance that an ethical climate will inform research ethics and promote responsible publishing behavior.

Please visit the website of the International Society of Addiction Journal Editors (ISAJE) at www.isaje.net to access supplementary materials related to this chapter. Materials include additional reading, exercises, examples, PowerPoint presentations, videos, and e-learning lessons.

\section{References}

Alighieri, D. (1947). The Divine Comedy (translated by Laurence Binyon in The Portable Dante, The Viking Portable Library \#32). New York, NY: Viking Press.

Brody, H. (1990). Applied ethics: Don't change the subject. In B. Hoffmaster, B. Freedman, and F. Raser (Eds.), Clinical ethics: Theory and practice (pp. 183-200). Clifton, NJ: Human Press. 
Casswell, S. (2013). Why do we not see the corporate interests of the alcohol industry as clearly as we see those of the tobacco industry? Addiction, 108, 680-685. DOI: https://doi.org/10.1111/add.12011

Elwood, W. (1994). Rhetoric in the War on Drugs: The triumph and tragedy of public relations. Westport, CT: Praeger.

Fisher, C. B. (2011). Addiction research ethics and the Belmont Principles: Do drug users have a different moral voice? Substance Use \& Misuse, 46, 728-741. DOI: https://doi.org/10.3109/10826084.2010.528125

Farmington Consensus. (1997). Addiction, 92, 1617-1618. DOI: https://doi. org/10.1080/09652149736332

Glaser, J. W. (1994). Three realms of ethics: Individual, institutional, societal. Kansas City, MO: Sheed and Ward.

Institute of Medicine. (2002). Integrity in scientific research: Creating an environment that promotes responsible conduct. Washington, DC: National Academy of Sciences Press.

ISAJE Ethics Group. (2002). Ethical practice guidelines in addiction publishing: A model for authors, journal editors and other partners. London, England: International Society of Addiction Journal Editors. Retrieved from: www. isaje.net.

Jonsen, A. R., \& Toulmin, S. (1988). The abuse of casuistry: A history of moral reasoning. Berkeley, CA: University of California Press.

Kass, L. R. (2002). Life, liberty and the defense of dignity: The challenge of bioethics. San Francisco, CA: Encounter Books.

Lynch, W. J., Nicholson, K. L., Dance, M. E., Morgan, R. W., \& Foley, P. L. (2010). Animal models of substance abuse and addiction: Implications for science, animal welfare, and society. Comparative Medicine, 60, 177-188.

McGovern, T. F. (1998). Vulnerability: Reflection on its ethical implications for the protection of participants in SAMSHA programs. Ethics and Behaviour, 8, 293-304.

Miller, P. G., de Groot, F., McKenzie, S., \& Droste, N. (2011). Vested interests in addiction research and policy. Alcohol industry use of social aspect public relations organizations against preventative health measures. Addiction, 106, 1560-1567.

Ross, J. W., Glaser, J. W., Rasinski-Gregory, D., McIver Gibson, J., \& Bayley, C. (1993). Health care ethics committees: The next generation. Chicago, IL: America Hospital Publishing.

Thompson, E. S. (Ed.). (1980). The Meno of Plato. New York, NY: Garland Publishing.

White, W. L., \& Popovits, R. M. (2001). Critical incidents: Ethical issues in the prevention and treatment of addiction (2nd ed.). Bloomington, IL: Lighthouse Institute. 
